\title{
Gênero e educação: dissidências, resistências e transgressões
}

\author{
Daniela Grieco Nascimento e Silva ${ }^{1}$
}

Gustavo de Oliveira Duarte ${ }^{2}$

\begin{abstract}
Resumo
Este artigo aborda problemáticas referentes às discussões de gênero no contexto escolar no que tange às conformações culturais que definem e legitimam papéis sociais e reforçam binarismos. A partir de uma pesquisa teórica, são tecidas algumas ponderações sobre a produção e potência da conceitualização do termo gênero e sua relação com as produções das identidades masculinas e femininas, especialmente relacionando a atuação do discurso escolar em relação a estas temáticas. Perceber e pensar sobre as relações de poder que interagem na escola é uma forma de opor-se, de gerar resistência e tecer outro olhar, outra escuta, capaz de compreender e acolher as diversidades, vendo-as como uma forma de manifestação da identidade/subjetividade do sujeito.

Palavras-chave: Gênero; Contexto Escolar; Problematizações.
\end{abstract}

\section{Género y educación: disentimiento, resistencias y transgresiones}

\section{Resumen}

Este artículo aborda problemáticas referentes a las discussões de género en el contexto escolar en lo que atañe a las conformidades culturales que definen y legitiman roles sociales y refuerzan binarismos. A partir de una reflexión teórica, son hiladas algunas ponderaciones sobre la producción y potencia de la conceptualización del término género y su relación con las producciones de las identidades masculinas y femeninas, especialmente relacionando la actuación del discurso escolar en relación a estas temáticas. Comprender y ponderar sobre las relaciones de poder que interactúan en la escuela es una forma de oponerse, de generar resistencia e hilar una otra mirada, una otra escucha, capaz de comprender y acoger las diversidades, viéndolas como una forma de manifestación de la identidad/subjetividad del sujeto.

Palabras-clave: Género; Contexto Escolar; Cuestionamientos.

\section{Introdução}

Relatos no cotidiano dos espaços formais e informais de ensino apontam sobre as relações preconceituosas e/ou opressivas advindas de escolas no que diz respeito à intolerância quanto a diversidade de gênero ser recorrente, embora nunca tenhamos abordado

\footnotetext{
${ }^{1}$ Pós-Doutoranda em Gerontologia (UFSM); Doutora em Educação (UFSM); Diretora, Coreógrafa e Professora de Ballet da ONG Royale Escola de Dança e Integração Social - Santa Maria - RS; Professora de Ballet da UFSM Companhia de Dança. Santa Maria - RS - E-mail: daninasc21@gmail.com.

${ }^{2}$ Pós-Doutor em Dança - UFBA, Doutor em Educação - UFRGS/RS, Mestre em Educação- UFSM/RS, Professor dos Cursos de Dança licenciatura e Educação Física Licenciatura (UFSM), Coordenador do GEEDAC e do LICOR, Vice-Diretor do Centro de Educação Física e Desportos -CEFD - UFSM. Santa Maria - RS - E-mail: guto.esef@gmail.com.
} 
o tema com tamanha amplitude em nossa atualidade. Da mesma forma, discursos que definem os corpos a partir de normas e padrões estetizados continuam a exercer poder desde a edificação de infâncias atreladas as mais variadas produções culturais do entretenimento e que, sutilmente contribuem para criar, legitimar e difundir formas de ser e estar no mundo. Diante desse interim, percebe-se a constante necessidade de dialogarmos acerca de binarismos veiculados pela cultura do mundo ocidental e as possibilidades que podemos articular de seu desmantelamento por abordagens menos rígidas e mais adequadas à contemporaneidade.

A escola constitui-se como um contexto privilegiado no qual geralmente são iniciadas, ensinadas e aprofundadas as práticas de socialização, compreensão discursiva e definição de maneiras de atuar e relacionar-se. Logo seria conveniente refletir e problematizar como se constroem culturalmente as noções de identidades de gênero, ou seja, como seu discurso promove as interações, os comportamentos, as atitudes, as falas, as imagens masculinas e femininas que homens e mulheres constroem ao longo de suas vidas.

Desse modo, diferentes formas de masculinidade e feminilidade são forjadas por meio da educação escolar, marcando diferenças simbólicas entre meninos e meninas. Essas marcas serão reproduzidas ao longo da vida, unindo ou contrapondo identidade sexual a identidade de gênero. Ser homem e ser mulher é, de certa maneira, "ensinado" por meio do discurso escolar, pois "a escola é atravessada pelos gêneros; é impossível pensar sobre a instituição sem que se lance mão das reflexões sobre as construções sociais e culturais do masculino e feminino" (LOURO, 2008, p.89).

Portanto, a cultura escolar evidencia as diversas formas como meninos e meninas são vistos e tratados, articulando práticas e discursos que acentuam e marcam as diferenças. Nesse cenário a escola constitui-se como importante instrumento das relações de poder que se organizam no campo social, contribuindo para a produção das identidades e papéis de gênero de acordo com o meio cultural e social do indivíduo.

O conceito de gênero nasceu no final dos anos de 1960 durante a Segunda Onda do Movimento Feminista, quando as feministas anglosaxãs usaram o termo para caracterizar o discurso social e cultural a respeito das diferenças entre os sexos, contrapondo-se ao determinismo biológico vigente. Segundo essa perspectiva, gênero relaciona-se ao mundo simbólico que permeia o sujeito, estruturando-o em nível psíquico e social. Já sexo caracteriza 
o corpo biológico, marcado pelas diferenças anatômicas.

Ao longo da história do mundo ocidental o discurso hegemônico sempre esteve sobre dominação masculina, repassando o pensamento de uma sociedade patriarcal, branca, capitalista e heterossexual. As mulheres eram excluídas dos processos políticos, culturais e educacionais da sociedade, restritas aos seus lares, consideradas inferiores e totalmente submetidas à ordem masculina. De acordo com Michelle Perrot:

Efetuou-se, a partir do século 18, com o florescimento da biologia e da medicina, uma sexualização do gênero que era pensado, até então, em termos de identidade ontológica e cultural muito mais do que física. [...] Homens e mulheres são identificados por seu sexo; em particular as mulheres são condenadas a ele, ancoradas em seus corpos de mulheres chegando até a ser prisioneiras deles. Assiste-se, então, à biologização e à sexualização do gênero e da diferença entre os sexos. [...] Esta naturalização das mulheres, presas a seus corpos, à sua função reprodutora materna e doméstica, e excluídas da cidadania política em nome desta mesma identidade, traz uma base biológica ao discurso paralelo e simultâneo da utilidade social (PERROT, 2005, p.470).

Da mesma maneira, desenvolveu-se uma biopolítica das relações entre os sexos, ou seja, as identidades masculinas e femininas foram definidas a partir do discurso produzido sobre o biológico. Construiu-se a identidade sexual que passaria a determinar e diferenciar homens e mulheres, organizando racionalmente a sociedade e a cultura. É este argumento naturalista que possibilita a criação da teoria das esferas, identificando o público (que envolve participação política e social) com o universo masculino, e o privado (restrito ao lar e a submissão), ao feminino. Assim, a diferença sexual se tornou a base para a discriminação política e social das mulheres.

Quando a exclusão das mulheres da cidadania foi legitimada pela referência às diferenças biológicas das mulheres e dos homens, a 'diferença sexual' foi estabelecida não somente como um fato natural, mas também como uma base ontológica para a diferenciação política e social (SCOTT, 2009, p.21).

As mulheres se tornaram praticamente invisíveis, foram silenciadas em seus lares, com uma função restrita apenas à reprodução e à maternidade. A educação se restringia ao mínimo indispensável para auxiliar na educação dos filhos e à administração da casa com eficiência. 
Mas, segundo destaca Guacira Louro (2008), ao longo do tempo algumas vozes femininas conseguiram elevar-se acima do socialmente aceito, reivindicando isoladas ou em conjunto, reformas políticas, sociais e educacionais em favor das mulheres.

A historiadora, jornalista e escritora francesa Olympe de Gouges (pseudômino de Marie Gouze) é considera uma das primeiras feministas da história. Participante ativa da Revolução Francesa, Olympe escreveu em 1791 a "Declaração dos Direitos da Mulher e do Cidadão" em contraponto a "Declaração dos Direitos do Homem e do Cidadão" que excluía as mulheres dos processos de decisão política.

De início, a Revolução Francesa define uma cidadania seletiva em seu conteúdo e em seus protagonistas. A cidadania civil é distinta da cidadania política. As mulheres têm acesso a primeira, em uma certa medida e até certo ponto, mas que não pode ser negligenciável. [...] Elas são cidadãs passivas como as crianças, os pobres e os estrangeiros (PERROT, 2005, p.329).

Olympe de Gouges lutava pela autonomia e a liberdade feminina, defendendo a participação política plena das mulheres na sociedade, de modo que fossem também incluídas como cidadãs. Acusada de ocupar-se com temáticas que não interessavam à revolução, Olympe foi guilhotinada em 1793.

Posteriormente, com a Revolução Industrial e a maior inserção das mulheres no mercado de trabalho formal, seguindo os moldes do modelo capitalista (principalmente como operárias, vendedoras e costureiras) surgiram novas batalhas que visavam maior participação política feminina na sociedade. É importante destacar que as mulheres, desde o início da humanidade, sempre estiveram incluídas no universo de trabalho, ainda que informalmente e sem remuneração. Essas lutas começaram a desenrolar-se com maior ênfase no final do século XIX e início do século XX quando as mulheres (principalmente as europeias e norte-americanas) iniciaram a exigência pelo voto feminino, promovendo as agitações sufragistas, ainda que estas eram privilegiadas, na época, por serem mulheres brancas e burguesas, que podiam circular em espaços proibidos por mulheres brancas pobres e negras. Esse movimento, que pedia maior participação política e igualdade entre os sexos, espalhou-se por diversos países e foi considerado a Primeira Onda do Movimento Feminista. 
As feministas da primeira onda não usavam a palavra diferença, empenhadas que estavam em transformar o sexismo, isto é, o discurso misógino convencional acerca da diferença entre os sexos, no discurso andrógino da abstrata indistinção de natureza entre homens e mulheres e, nesse registro, conquistar para as mulheres oportunidades, postos e direitos iguais aos homens. Com que então, podemos dizer que a primeira onda de teorização feminista foi basicamente igualitarista (PIERUCCI, 2007, p.31).

Mas, cabe salientar que as feministas da primeira onda (denominadas feministas liberais) eram mulheres brancas, de classe média e classe média alta. As mulheres de classe média alta, donas de propriedades, tinham como força motriz de suas reivindicações não serem oprimidas pelos homens de sua classe, removendo-se as diferenças entre elas e os homens que também possuíam propriedades.

As mulheres de classe média, por sua vez, tinham como ponto central a igualdade de oportunidades no treinamento profissional e no mercado de trabalho em relações aos homens de sua classe, os quais geralmente tinham força de trabalho qualificada e bons postos de trabalho.

Já as mulheres pobres que trabalhavam nas fábricas em jornadas exaustivas, em condições precárias e por baixíssimos salários, trabalhavam fora e deixavam seus filhos em casa, tinham dupla jornada por também realizarem os serviços domésticos e, consequentemente, possuíam outra vivência e ponto de partida para lutarem por seus direitos.

De toda forma, o movimento sufragista uniu diferentes grupos de mulheres, de diferentes classes sociais, de diferentes raças, com diferentes graus de instrução e com diferentes pautas, mas que tinham uma experiência comum: a exclusão dos direitos políticos. Essa exclusão interferia no alcance de seus objetivos, fossem eles relacionados à administração de posses, à educação formal, ao divórcio ou a melhores condições de vida e trabalho. $\mathrm{O}$ direito ao voto e de ser votada, era, antes de tudo, um reconhecimento da cidadania das mulheres.

O movimento da Primeira Onda combatia toda espécie de subordinação às mulheres, como também colocava em pauta questões relacionadas à liberdade sexual, mas acabou perdendo força na década de 1930, só ressurgindo em 1960.

Foi no final da década de 1960 que se iniciou, de acordo com Pierucci (2007), a chamada Segunda Onda do Movimento Feminista, que além das reivindicações sociais e políticas das mulheres, preocupou-se em tecer um corpo teórico que pudesse problematizar o universo 
feminino em toda a sua singularidade, surgindo os estudos sobre a mulher e destacando as diferenças entre os sexos. A obra "O Segundo Sexo", da filósofa francesa Simone de Beauvoir, é considerada um marco fundamental para a teoria feminista, tendo exercido grande influência em relação aos estudos sobre as mulheres.

O movimento da Segunda Onda foi marcado por uma grande efervescência intelectual, de contestações e inúmeras transformações políticas e culturais que modificaram não apenas o universo feminino, mas todas as relações sociais dali para frente. Esse movimento teve como foco as relações de poder presentes nas sociedades, reivindicando maior representação política e autonomia para as mulheres decidirem sobre suas vidas e sobre seus corpos.

Segundo destaca Guacira Louro (2008), o conceito de gênero surgiu a partir desta contestação, do final dos anos de 1960, do discurso social vigente, o qual argumentava que eram as características biológicas as responsáveis pelas desigualdades sociais entre homens e mulheres.

Nesse cenário, foram as feministas anglosaxãs que começaram a usar o termo gênero em distinção ao termo sexo, procurando rejeitar o determinismo biológico e acentuar por meio do discurso o caráter social das diferenças baseadas no sexo. Desse modo, "não é negada a biologia, mas enfatizada, deliberadamente, a construção social e histórica produzida sobre as características biológicas" (LOURO, 2008, p.22).

Diante disso, o sexo passa a ser considerado o dado biológico expresso pelo corpo, que corresponde à diferença anatômica e ao geneticamente herdado. Gênero refere-se ao discurso social produzido a respeito do corpo, ao modo como as características sexuais são compreendidas e representadas a nível simbólico, cultural e social. Distingue-se, assim, a identidade sexual da identidade de gênero dos sujeitos que são entendidas como:

\footnotetext{
Suas identidades sexuais se constituem, pois, através das formas como vivem sua sexualidade, com parceiros/as do mesmo sexo, do sexo oposto, de ambos os sexos ou sem parceiros. Por outro lado, os sujeitos também se identificam, social e historicamente, como masculinos e como femininos e assim constroem suas identidades de gênero (LOURO, 2008, p.26).
}

As identidades sexuais e de gênero têm como principal referencial o corpo do sujeito, que é significado, representado e interpretado culturalmente, sendo que tais identidades estão 
sempre em correlação e se autoinfluenciam. A identidade de gênero irá se relacionar ao sentimento de identidade individual, sendo as convicções construídas socialmente por um sujeito sobre o que é ser homem ou mulher em uma cultura determinada. O núcleo dessas convicções não muda ao longo da vida, mas o sujeito pode agregar novos papéis sociais a tais convicções.

Assim, a identidade de gênero do sujeito não é herdada, mas sempre produzida no registro social, ou seja, não é fixada no nascimento, mas possui um caráter plástico que vai moldando-se conforme as vivências, experiências e convivências - está em transformação permanente articulando-se às histórias pessoais, às identidades sexuais, aos papéis sociais, com à etnia e à classe social.

\section{Sobre a performatividade de gênero}

Judith Butler (2013) enfatiza que as identidades sexuais e de gênero, bem como os papéis relacionados a cada gênero, são edificadas e estabelecidas pela linguagem, ou seja, o gênero e o sexo se constroem por meio do discurso social, no momento em que são nomeados e classificados de acordo com os princípios socialmente aceitos sobre masculino e feminino dentro de determinada cultura.

Como em outros dramas sociais rituais, a ação do gênero requer uma performance repetida. Essa repetição é a um só tempo reencenação e nova experiência de um conjunto de significados já estabelecidos socialmente; e também é a forma mundana e ritualizada de sua legitimação. Embora existam corpos individuais que encenam essas significações estilizando-se em formas do gênero, essa ação é uma ação pública. Essas ações têm dimensões temporais e coletivas, e seu caráter público não deixa de ter consequências, verdade, a performance é realizada com o objetivo estratégico de manter o gênero em sua estrutura binária - um objetivo que não pode ser atribuído a um sujeito, devendo, ao invés disso, ser compreendido como fundador e consolidador do sujeito (BUTLER, 2013, p.200).

Dentro desse contexto, o gênero se faz, e se desfaz, por meio das palavras que irão significar o corpo do sujeito. As normas de regulação do gênero se materializam no corpo efetuando uma inscrição cultural a serviço da heteronormatividade, que assinala como norma 
social e cultural a heterossexualidade. Ou seja, na performatividade proposta por Judith Butler o corpo é significado pela linguagem, fazendo-se em seus próprios atos e ações, mas sempre de acordo com o estabelecido pelo meio social.

Portanto o termo perfomatividade utilizado por Judith Butler não se relaciona à terminologia performance, em que existe um ator que desempenha um papel previamente estipulado. Perfomatividade remete a uma ação do discurso sobre os corpos dos sujeitos, que reproduzirão gestos, movimentos, posturas, atos etc., de acordo com o que é estabelecido para seu gênero em sua cultura. Enquanto na performance existe um sujeito consciente do papel que executa, na performatividade o sujeito vai constituindo-se desde o nascimento por meio de seus atos e gestos, não tendo consciência plena que os mesmos o criam e o significam.

O corpo é atravessado pelas relações de poder, que são reproduzidas por meio do discurso, em uma rede permanente de fabricação de significados linguísticos, em que sujeito, discurso e meio social interagem permanentemente, num processo contínuo de criação e recriação. No momento em que a linguagem nomeia o corpo do sujeito como macho ou como fêmea seu sexo é performaticamente elaborado, sendo categorizado e normatizado pelo meio cultural. A linguagem, desse modo, não apenas descreve o corpo, mas o constitui como sujeito dentro de uma determinada sociedade, pois esse corpo não é apenas descrito, mas "constituído pelo próprio ato de descrição" (SALIH, 2013, p.125).

Gênero e sexo são construídos, portanto pela linguagem e pelo discurso, que são suas causas de constituição. Assim, para Judith Butler (2013), o sujeito é sempre efeito e prática dos atos discursivos do meio social e cultural, sendo que a produção de gênero se constitui em um processo singular, em constante edificação, que varia de sujeito para sujeito relacionando-se também à sexualidade, à classe e à etnia.

Sara Salih (2013) assegura que a existência do sujeito é sempre social e que os corpos são atravessados por processos de generificação, não existindo um corpo neutro ou natural, pois todos recebem sua inscrição cultural, muitas vezes, antes do nascimento. Antes de ser concebida uma criança já é mencionada, falada, idealizada e tem seu espaço constituindo-se mesmo sem sua presença efetiva. Quando nasce, já encontra uma estrutura familiar operando, composta de lugares, histórias e mitos. Insere-se, logo, em uma cadeia linguística que, certamente, é referida aos seus pais, mas ultrapassa-os, à medida que, o que a estes se refere já foi inscrito nas gerações 
anteriores. A inscrição cultural marca, produz, diferencia os corpos, fazendo circular discursivamente as diferenças sexuais que, ao construírem simbolicamente o corpo, o regulam e o governam. Assim, "gênero não é algo que somos, é algo que fazemos, um ato, ou mais precisamente, uma sequência de atos, um verbo em vez de um substantivo, um fazer em vez de $\operatorname{ser}^{\prime \prime}($ SALIH, 2013, p.89).

Ao enfatizar o caráter de edificação permanente e performativo do gênero através do tempo e da cultura, as teorias feministas se aproximam das teorias da construção social ao também contestar o determinismo biológico e defender a identidade como um processo sempre aberto às transformações, pois o sujeito é elaborado constantemente por meio da cultura. Ademais, como a cultura está em permanentemente transformação, o sujeito se modifica conjuntamente com ela (BRUNER, 1990, p.47).

Ao se conceber no coletivo, por meio de suas relações e interações diárias, o sujeito vai assumindo novos modos de ser, em um eterno processo de edificação. Então, a compreensão identitária do sujeito jamais será fixa e estável, mas se constitui em um processo aberto, em constante transformação, redefinindo-se continuamente.

Conforme Judith Butler (2013), no momento em que ocorre uma identificação do sujeito com o gênero determinado por sua cultura e sua sociedade, ele incorpora seu receptivo papel de gênero, executando uma perfomatividade que se constitui em um efeito discursivo do poder, mas que se encontra em produção permanente, pois, ao mesmo tempo em que o sujeito é influenciado pelo poder, pode também oferecer atos de resistência e de transgressão ao próprio poder.

Essa subjetividade das relações de gênero levou a repensar a dicotomia masculino / feminino evidenciada pela Segunda Onda do Movimento Feminista. Tendo a multiplicidade feminina e as relações de poder entre as mulheres como focos, surge a Terceira Onda do Movimento Feminista que:

Além do gênero, dois outros sistemas de poder passaram a figurar como imprescindíveis: a raça e a classe. Isso quer dizer que, do enfoque binário de gênero, a legitimidade acadêmica foi logo se deslocando para essa poderosa tríade: gênero, classe e raça. Surgia assim uma produção científica que, interessada nas relações de poder entre as mulheres, passou a fixar a atenção nas mulheres de diferentes raças e diferentes culturas de classe (PIERUCCI, 2007, p.42-43). 
São as relações de poder que instituem e nomeiam as diferenças e desigualdades não apenas entre os gêneros, mas também entre a raça, a etnia e a classe. A opressão das mulheres, então, possui uma forma singular de acordo com sua etnia, sua condição econômica, sua cultura, sua classe social, estando ligada ao discurso de uma determinada sociedade em um momento histórico específico.

Existem múltiplas mulheres: negras, brancas, amarelas, indígenas, heterossexuais, bissexuais, homossexuais, feministas liberais, feministas socialistas, feministas anarquistas etc., de maneira que os estudos sobre as mulheres a partir do movimento da Terceira Onda precisavam abarcar todas as diversidades existentes no universo feminino e feminista em suas apreciações, pois a história dos movimentos minoritários é sempre particular e nunca universal.

No momento em que os estudos feministas se centram em teorizar sobre uma identidade feminina única, referindo-se a uma mulher universal, acabam fixando-se em um modelo que não poderá dar conta da multiplicidade de mulheres, que são diversas, vivendo em culturas diversas, com problemáticas femininas diversificadas. Tentar estabelecer uma única identidade feminina, compartilhada por todas as mulheres, será estabelecer uma padronização e normatização da conduta feminina.

Para Judith Butler (2013), a ideia de sujeito será sempre um efeito das práticas discursivas do poder, sendo que o corpo será elaborado discursivamente pelo discurso e pela lei. Desse modo, são as relações de poder presentes nas sociedades que produzem as discriminações e exclusões que são justificadas e legitimadas muitas vezes em termos de gênero, sexualidade, raça, classe e etnia. Assim, a produção das diferenças está relacionada às redes de poder que circulam no meio social.

Parece-me que se deve compreender o poder, primeiro, como a multiplicidade de correlações de forças imanentes ao domínio onde se exercem e constitutivas de sua organização; o jogo que, através de lutas e afrontamentos incessantes, as transforma, reforça, inverte; os apoios que tais correlações de forças encontram umas nas outras, formando cadeias ou sistemas, ou ao contrário, as defasagens e contradições que as isolam entre si; enfim, as estratégias em que se originam e cujo esboço geral ou cristalização institucional toma corpo nos aparelhos estatais, na formulação da lei, nas hegemonias sociais [...] O poder não é uma instituição nem uma estrutura, não é uma certa potência de que alguns sejam dotados: é o nome dado a uma situação estratégica complexa numa sociedade determinada (FOUCAULT, 2014, p.100- 101). 
De acordo com Michel Foucault (2014), o poder constitui-se em um jogo de forças que existem em uma sociedade. São esses jogos de forças que originam os aparelhos de estado e as dominações ideológicas predominantes no meio social. O poder está em toda a parte e vai transformando-se segundo as mudanças sociais, não tendo um núcleo central, pois é formado pela multiplicidade de forças que existem no entorno. Essa multiplicidade é constituída por forças desiguais que levam continuamente a estados de poderes, que originam forças móveis, estáveis, que estão em constante transformação. O poder funciona como uma máquina, que dissemina suas forças por todo o entorno.

Compreendemos que os sujeitos não são seres passivos frente ao poder, pois no momento em que o poder circula pelo meio social, envolve os sujeitos em suas tramas de maneira que ao ser atingido pelo poder, o sujeito não será meramente submetido a ele, mas poderá exercê-lo, tornando-se não apenas um receptor, mas também um transmissor do poder. Assim, o sujeito não é simplesmente instituído pelo poder, mas também atravessado pela rede de poderes que circulam na sociedade, sendo que o poder não representa algo material ou mensurável, mas se efetiva por meio de práticas que funcionam através de dispositivos ou mecanismos, constituindo as relações de poder em uma ação social.

As forças de poder são imanentes em todas as relações: as relações de poder são sempre intencionais, sempre visam um objetivo. Por outro lado, as resistências ao poder são múltiplas e ocorrem dentro da própria rede onde circulam os poderes, distribuindo-se de maneira irregular disseminando-se nos sujeitos. Assim, podemos pensar que o poder funciona como uma teia, no qual as resistências a ele ocorrem dentro da própria teia, irradiando suas forças e afetando toda a rede.

\section{Saberes e poderes que atravessam a escola}

Todo poder carrega consigo um saber que se constrói na interação entre sujeito e meio social, pois "todo ponto de exercício de poder é, ao mesmo tempo, um lugar de formação de saber" (FOUCAULT, 2013, p.28). Poder e saber estão sempre relacionados, sempre ligados, em um processo de legitimação recíproca, exercendo-se sobre os corpos dos sujeitos. Assim, o sujeito individual constitui-se em uma produção do saber e do poder. 
O saber está basicamente ligado a questão do poder na medida em que a partir da Idade Clássica, é por meio do discurso da racionalidade - isto é, a separação entre o científico e o não científico, entre o racional e o não racional, entre o normal e o anormal - que será efetuada uma ordenação geral do mundo, quer dizer, também dos indivíduos, que passam ao mesmo tempo, por uma forma de governar (o Estado) e por processos disciplinares (REVEL, 2011, p.134).

Nesse sentido, os saberes surgem como dispositivos do poder legitimando-se pelo conhecimento científico que originam. Foi a partir dos séculos XVII e XVIII, que o poder se direcionou no domínio do corpo do sujeito, a fim de torná-lo mais produtivo e eficiente. Surgindo o regime disciplinar que se constitui em um conhecimento sistematizado pelo poder político e econômico a fim de exercer total controle sobre os sujeitos objetivando estabelecer maior desenvolvimento econômico e estabilidade política. Para tal desenvolve técnicas de vigilância e repressão sobre seus corpos, pois:

O momento histórico das disciplinas é o momento em que nasce uma arte do corpo humano, que visa não unicamente o aumento de suas habilidades, nem tampouco aprofundar sua sujeição, mas a formação de uma relação que no mesmo mecanismo o torna tanto mais obediente quanto é mais útil, e inversamente. Forma-se então uma política das coerções que são um trabalho sobre o corpo, uma manipulação calculada de seus elementos, de seus gestos, de seus comportamentos. O corpo humano entra em uma maquinaria de poder que o esquadrinha, o desarticula e o recompõe. Uma "anatomia política", que é também igualmente uma "mecânica do poder", está nascendo; ela define como se pode ter domínio sobre o corpo dos outros, não simplesmente para que façam o que se quer, mas para que operem como se quer, com as técnicas, segundo a rapidez e a eficácia que se determina (FOUCAULT, 2012, p.133).

Seguindo esse pensamento, entende-se que o regime disciplinar controla o espaço, o tempo, os movimentos, os gestos dos sujeitos a fim de torná-los mais produtivos e, logo, submetidos ao poder, isto é, que esta produção seja eficiente para a manutenção do poder. A disciplina utiliza várias técnicas para atingir seus objetivos, criando saberes e métodos capazes de transformar a população em uma pluralidade organizada e submissa. Para isso, a disciplina constitui instituições disciplinares que auxiliam na propagação de suas técnicas e discursos, como os exércitos, os hospitais, as indústrias e as escolas. Nascem corpos dóceis (FOUCAULT, 2012), que são capazes de ser utilizados e contornados segundo as vontades e os interesses do 
poder. São corpos exauridos de intensidades que apenas repetem e difundem os mesmos enunciados de eficiência e competição.

A disciplina fabrica assim corpos submissos e exercitados, corpos 'dóceis'. A disciplina aumenta as forças do corpo (em termos econômicos de utilidade) e diminui essas mesmas forças (em termos políticos de obediência). Em uma palavra: ela dissocia o poder do corpo; faz dele por um lado uma 'aptidão', uma 'capacidade' que ela procura aumentar; e inverte por outro lado a energia, a potência que poderia resultar disso, e faz dela uma relação de sujeição estrita. Se a exploração econômica separa a força e o produto do trabalho, digamos que a coerção disciplinar estabelece no corpo o elo coercitivo entre uma aptidão aumentada e uma dominação acentuada (FOUCAULT, 2012, p.133-134).

Surgem os corpos-fábricas, os corpos-soldados, os corpos-doentes, os corpos- alunos, cada um tendo o mesmo intento de disciplinar e sujeitar os indivíduos por meio da submissão total dos seus corpos. Dentro desse contexto, muitas escolas tornam-se instituições disciplinares regidas por leis autoritárias, nas quais o saber cartesiano é ligado ao poder político. O professor, por exemplo, pode tornar-se proprietário e transmissor de todo o saber, submetendo os estudantes ao seu poder, que serão avaliados por meio de exames para serem classificados, selecionados e recompensados de acordo com seus méritos.

Assim, é possível que o espaço escolar tenha se configurado como classe homogênea na qual cada sujeito compõe o todo, sendo observado e vigiado pelo mestre, instituindo o poder panóptico que "funciona como uma espécie de laboratório de poder. Graças a seus mecanismos de observação, ganha em eficácia e em capacidade de penetração no comportamento dos homens; um aumento de saber vem se implantar em todas as frentes do poder, descobrindo objetos que devem ser conhecidos em todas as superfícies onde se exerça" (FOUCAULT, 2012, p.194).

A disciplina do poder panóptico ${ }^{3}$ por meio da força do olhar, possibilitou o controle sobre os sujeitos, de modo a torná-los dóceis e úteis à sociedade, propiciando o surgimento de uma sociedade de controle. Michel Foucault (2013) define, nesse contexto, duas formas de

\footnotetext{
${ }_{3}^{3}$ Panóptico corresponde à construção de uma prisão, cujo desenho foi criado pelo filósofo Jeremy Bentham, que permite que se observe toda a totalidade a partir de um único ponto. Utilizando-se dessa compreensão Michel Foucault idealizou o conceito de panóptico, que se estendeu das cadeias para outras instalações, como as escolas e fábricas, convertendo-se em uma técnica de controle da população.
} 
poder: o poder disciplinar, que se aplica ao corpo por meio das técnicas de vigilância e das instituições punitivas; e o poder ao qual ele denomina de biopoder, que se exerce sobre a população e que vai controlar não apenas os corpos individuais, mas a totalidade do corpo social.

Além disso, Foucault (2012) situa que a disciplina irá modelar os corpos individuais a fim de formar uma multiplicidade competente e produtiva. Não reduz forças, mas multiplica forças. Faz o individual se transformar em uma multiplicidade homogênea que será útil para o processo de expansão e dominação do capitalismo, que reconhece o corpo como uma vital potência de trabalho e produção de lucros.

A escola, sob esse prisma, constitui-se em uma importante instituição disciplinar e ao longo de sua história, foi a principal reprodutora do discurso da sociedade ocidental, legitimando os poderes político e econômico além de reproduzir padrões e normas de comportamentos a serem internalizados pelos sujeitos. Louro (2008) destaca que:

A escola delimita os espaços. Servindo-se de símbolos e códigos, ela afirma o que cada um pode (ou não pode) fazer, ela separa e institui. Informa o 'lugar' dos pequenos e dos grandes, dos meninos e das meninas. Através de seus quadros, crucifixos, santas ou esculturas, aponta aqueles/as que deverão ser modelos e permite, também, que os sujeitos se reconheçam (ou não) nesses modelos. O prédio escolar informa a todos/as sua razão de existir. Suas marcas, seus símbolos e arranjos arquitetônicos 'fazem sentido', instituem múltiplos sentidos, constituem distintos sujeitos (LOURO, 2008, p.58).

Seguindo este pensamento, impregnado pelas relações de poder existentes na sociedade, o espaço escolar não apenas propaga o discurso ideológico do meio social nos diferentes períodos históricos, mas também auxilia a edificar simbolicamente e culturalmente as identidades e os papéis de gênero dos sujeitos, escrevendo em seus corpos, através de papéis, práticas e discursos, as representações do masculino e do feminino socialmente e culturalmente desejado pelo meio social. Assim, forma-se, de modo sutil e quase imperceptível, um corpo escolarizado, marcado e reconhecido, por meio de posturas e atos, pela ideologia da instituição escolar que frequenta/frequentou, pois "o poder disciplinar não destrói o indivíduo; ao contrário, o fabrica. O indivíduo não é o outro do poder, realidade exterior, por ele anulado; é um dos seus mais importantes efeitos" (FOUCAULT, 2013, p.25). 
A disciplina, como instrumento de poder, controla e normatiza os sujeitos no momento em que produz corpos escolarizados por meio da manipulação e do condicionamento. Surgem, nas escolas, mecanismos de controle dos alunos como as filas, as classes, os horários, os testes, o treinamento de habilidades, a avaliação das capacidades, formando saberes que rotulam negativamente os e as estudantes (alunos problemáticos, alunos indisciplinados etc.) e saberes que enaltecem (o bom aluno, o excelente aluno etc.).

Por conseguinte, o poder disciplinar produz efeitos de verdade que são reproduzidos. Logo, como todo o poder, encontra-se sempre focos de resistências que geram transgressões, isto é, no contexto escolar, os rótulos produzidos pela escola em relação aos alunos que não seguem o padrão preestabelecido que propiciam o surgimento de novos saberes sobre a aprendizagem, a avaliação, a psicologia escolar, efetivando mudanças no espaço da escola e nas práticas pedagógicas dos professores. Pode-se dispor que o poder não é somente repressivo, "mas que de fato ele permeia, produz coisas, induz ao prazer, forma saber, produz discurso" (FOUCAULT, 2013, p.45). Foram os discursos produzidos pela escola que possibilitaram a edificação de novos saberes sobre o corpo e a aprendizagem, gerando novos olhares sobre os sujeitos.

June Hahner (2003) dispõe que a educação das mulheres no Brasil nos anos finais do século XIX era centrada em sua preparação para o casamento e a maternidade, contexto no qual deveriam transmitir virtudes morais para seus filhos. Era uma educação que refletia o olhar masculino sobre o papel social das mulheres e que levava em conta não apenas o gênero, mas também as diferenças de raça, de classe e de etnia. Hahner (2003) afirma que:

Aos homens, além de estabelecer quais os assuntos e as matérias que as mulheres deveriam estudar na escola, também lhes cabia escrever os textos e aprovar os livros que elas deveriam ler. Esta literatura prescritiva incorporava os valores relativos à socialização da mulher, assim como igualmente refletia as atitudes culturais e as preferências emanadas da percepção masculina dos papéis dos gêneros dentro da sociedade brasileira do século XIX (HAHNER, 2003, p.126).

Mesmo com a reforma educacional de 1879 que colocou a educação superior ao alcance das mulheres, o discurso masculino continuava a propagar que elas deveriam dedicarse exclusivamente ao lar e à criação dos filhos. As mulheres da classe trabalhadora também 
não tinham acesso a uma educação que pudesse proporcionar-lhes uma formação profissional que as auxiliasse economicamente, já a maioria exercia atividades com baixa remuneração e eram muitas vezes exploradas, ganhando um salário muito inferior ao dos homens nas mesmas ocupações (operárias, vendedoras, costureiras) e sofrendo, várias vezes, assédio sexual em seus locais de trabalho. Ademais, cabe salientar que a educação secundária e superior era um privilégio apenas das mulheres da elite.

Mas, mesmo assim, as mulheres começaram a exercer algumas atividades fora do lar, iniciando a feminilização de algumas profissões, ou seja, fixando-as em relação ao gênero feminino. A feminilização do magistério ocorreu no final do século $X I X$, sendo causada pela crescente industrialização e urbanização do país, que levou os homens a buscarem novos interesses econômicos, mais rentáveis e com mais status social. Os espaços masculinos na docência começaram então a ser ocupados pelas mulheres. De acordo com Guacira Louro (2013):

A partir de então passam a ser associadas ao magistério características tidas como tipicamente femininas: paciência, minuciosidade, afetividade, doação. Características que, por sua vez, vão se articular a tradição religiosa da atividade docente, reforçando ainda a ideia de que a docência deve ser percebida mais como um sacerdócio do que como uma profissão. Tudo foi muito conveniente para que se constituísse a imagem das professoras como trabalhadoras dóceis, dedicadas e pouco reivindicadoras, o que serviria futuramente para lhes dificultar a discussão de questões ligadas a salário, carreira, condições de trabalho, etc. (LOURO, 2013, p.450).

Nesse sentido, a sociedade permitia ações fora do lar para as mulheres, mas com caráter transitório, que deveria ser abandonada com o casamento, considerado a verdadeira vocação feminina. Tal caráter provisório justificava os baixos salários femininos, já que o provedor do lar era o homem. Assim, o magistério era visto predominantemente como uma vocação ao invés de uma profissão, sendo considerado um trabalho "digno" para as mulheres. Construía-se, assim, uma imagem idealizada da professora, que para apossar-se e transmitir o conhecimento deveria ser dedicada, submissa, assexuada, indo ao encontro à representação da "mulher digna" da época, quando a moral se definia a partir do pensamento masculino que não relaciona a sexualidade feminina ao prazer, mas a apenas à reprodução e aos cuidados da 
família sacralizados pelo matrimônio. Além disso, como a educação é concebida como um modo de controle da população, as mulheres deveriam ocupar seu lugar estipulado pelo poder hegemônico, não se desviando do rumo pré estabelecido para seu gênero.

O espaço escolar que iria formar as futuras professoras era permeado pelas relações de poder predominantes na sociedade, criando uma formação não apenas intelectual, mas moral e disciplinar, em que a ética e a estética criavam um corpo de professora. Essa normatização do corpo de professora diz respeito à visão de corpo dócil afirmada por Michel Foucault (2013), constituindo-se como um corpo adestrado, submetido, formado por meio de processos e de saber, de descrições, de receitas e dados. A representação da professora firmada pelo discurso masculino constitui-se em um processo social que não apenas fabrica um corpo de professora, mas faz com que as professoras se reconheçam nessa representação, definindo-se e assumindo-se segundo esses enunciados. Sobre este aspecto, Louro (2013) ressalta que

Muito provavelmente mulheres que tomassem iniciativas que contrariassem as normas, que tivessem um nível de instrução mais elevado ou que ganhassem seu próprio sustento eram percebidas como desviantes, como uma ameaça aos arranjos sociais e a hierarquia dos gêneros de sua época. Vale lembrar ainda que, por muito tempo, a ignorância foi considerada como indicador de pureza, o que colocava as mulheres não ignorantes como não puras. De certa forma elas escapavam a representação do senso comum sobre o ser feminino, escapavam da representação que detinha a autoridade para dizer o que era ser mulher (LOURO, 2013, p.469).

Os atos de rebeldia ao poder eram vistos como uma afronta à imagem idealizada da professora e da representação feminina firmada pelo discurso patriarcal. Muitas mulheres que ousaram romper com esses estereótipos eram marginalizadas pela sociedade e muitas conheciam o exílio social.

Mas, como as imagens evoluem segundo o processo histórico, à medida que as mulheres começaram a lutar por seus direitos na sociedade a imagem da professora foi modificando-se. As professoras começaram a reconhecerem-se como profissionais da educação, organizando-se como movimento social e passando a reivindicar seus direitos. Louro (2013) pontua: 


\begin{abstract}
Efetivamente é um outro sujeito social que se constitui. A professora sindicalizada, denominada de trabalhadora da educação, é representada pela mulher militante, disposta a ir as ruas lutar por melhores salários e melhores condições de trabalho. Ela deve ser capaz de parar suas aulas; gritar palavras de ordem em frente a palácios e sedes de governo; expor publicamente sua condição de assalariada, não mais de mãe, tia ou religiosa, e exigir o atendimento de seus reclamos. Face a discreta professorinha do início do século, o contraste parece evidente; são outros gestos, outra estética, outra ética (LOURO, 2013, p.474).
\end{abstract}

Mesmo como essa transformação da figura da professora, a educação escolar continua evidenciando as diferenças de gênero de modo marcante na maneira como são percebidas e justificadas as diferenças de comportamento e desempenho escolar. Enquanto as meninas são descritas como meigas, tranquilas, quietas, estudiosas e com bom desempenho escolar, os meninos são vistos como inquietos, curiosos, barulhentos, inteligentes e, com devidas exceções, com médio ou baixo rendimento escolar.

Tal fato demonstra não apenas as diferenças de concepções sobre masculino e feminino, mas acima de tudo, propaga a suposta "superioridade" intelectual masculina reforçada, muitas vezes, pelo discurso escolar, pois "enquanto o bom desempenho escolar das meninas era atribuído ao seu esforço, o desempenho inferior dos garotos era percebido como não realização de um potencial brilhante devido ao seu comportamento ativo" (CARVALHO, 2004, p.561). Essas ideias estão sempre associadas ao poder, sendo construídas dentro das relações de poder. Foi e segue sendo o discurso masculino o responsável pela maior parte das edificações femininas, difundindo o imaginário da mulher ideal por meio dos enunciados proferidos pela instituição escolar. A escola, então, torna-se primordial para a formação das identidades e papéis de gênero.

Conforme evidencia Guacira Louro (2008), embora o espaço escolar tenha sido sempre associado com práticas educativas caracteristicamente femininas, guardando semelhanças com as ações das mulheres no lar em relação à educação de seus filhos, sua essência encontra-se enraizada no masculino, uma vez que o conhecimento do mundo ocidental foi prioritariamente elaborado pelos homens.

Portanto, é possível argumentar que, ainda que as agentes do ensino possam ser mulheres, elas se ocupam de um universo marcadamente masculino - não apenas porque as diferentes disciplinas escolares se construíram pela ótica dos

Periódico Horizontes - USF - Itatiba, SP - Brasil - e021041 
homens, mas porque a seleção, a produção e a transmissão dos conhecimentos (os programas, os livros, as estatísticas, os mapas; as questões, as hipóteses e os métodos de investigação 'científicos' e válidos; a linguagem e a forma de apresentação dos saberes) são masculinos (LOURO, 2008, p.89).

Desse modo, o currículo, os processos avaliativos, as práticas pedagógicas, a organização escolar são fortemente determinadas e hierarquizadas pelas relações de poder, refletindo não apenas as relações de gênero, mas também de classe, de etnia e de raça. Procura-se, então, na educação escolar produzir homens e mulheres identificados com o padrão social vigente, que possam reproduzir valores e ideologias, ou seja, de uma sociedade capitalista, patriarcal, branca, heterossexual, masculina.

A educação escolar, produzida e enraizada pelo discurso masculino, produz uma identidade de gênero de acordo com tais primícias, ou seja, diferencia a educação de meninos e meninas de maneira que os mesmos internalizem o discurso ideológico do seu meio social a e possam reproduzi-la em suas relações, pois "a identidade é uma atribuição cultural; que ela é sempre dita e nomeada no contexto de uma cultura" (LOURO, 2000, p.90).

O corpo dos alunos e alunas, bem como o corpo das professoras e professores, são representados culturalmente de acordo com a visão do seu meio social e cultural, pois o contexto histórico demonstra que a instituição escolar sempre procurou disciplinar o corpo, tornando-o dócil e obediente, de acordo com a visão dualista cartesiana.

Não se pode negar que o espaço escolar, tão fortemente influenciado pelo poder disciplinar, é permeado pelas questões de gênero de maneira que a elaboração de um pensamento sobre a escola precisa levar em conta as representações discursivas do masculino e do feminino. Além disso analisar como essas concepções refletem-se nas construções corporais e intelectuais de homens e mulheres que cruzam os muros escolares.

Portanto, a escola constitui-se como um espaço de edificação de identidades e de papéis de gênero fortemente ligada às relações de poder, colaborando para a manutenção das diferenças e desigualdades não apenas de gênero, mas também de classe, raça e etnia. Para que se efetivem mudanças na educação e nas relações de gênero é necessário lançar um novo olhar sobre os discursos propagados pela escola, procurando ouvir a voz dos corpos silenciados e domesticados pela instituição escolar. 


\section{Algumas considerações}

Após tecer várias ponderações sobre o papel atribuído ao contexto escolar na concepção dos gêneros, considera-se necessário, desde os anos iniciais da formação escolar de meninas e meninos, desenvolver ações afirmativas que possibilitem perceber as diversidades como potências de igualdades, em que o "diferente" seja gerador de trocas interativas e solidárias entre os sujeitos.

Pensar o espaço escola como produtor de desigualdades e diferenças entre os gêneros, classes, sexualidade, raças e etnias significa um primeiro passo para começar a escrever uma outra história. Uma história que possa repensar e reconstruir os papéis atribuídos a homens e a mulheres; que possa movimentar o pensamento sobre a concepção das identidades e os papéis de gênero, de modo a respeitá-las em suas diversidades. Compreendemos e apontamos que tal movimento, tamanha sua relevância e simbolismo sociocultural, deva perpassar, efetivamente, mudanças significativas nos currículos de formação inicial e na própria formação continuada. Ainda necessitamos avançar para suprir a ausência de tais temáticas na maioria das universidades brasileiras, por meio de disciplinas obrigatórias e não somente, optativas.

Para isso, faz-se necessário refletir sobre os limites e as possibilidades da abordagem de temas como gênero e sexualidade nos currículos dos cursos de formação docente, sendo importante compreender a potência desses temas na promoção de uma cultura de igualdade, de respeito, de valorização da pluralidade. Compreende-se que a construção e a operação de um currículo estão sempre relacionadas aos modos pelos quais a educação vem sendo concebida historicamente. Nessa perspectiva, o currículo é um artefato social, cultural e histórico, implicado em relações de poder, que sempre transmite visões sociais interessadas. Um currículo é, ao mesmo tempo, modificado e modificador dos contextos em que opera (MOREIRA; SILVA, 1999). Desse ponto de vista, o currículo é um campo de luta, tensões e disputas em torno de significações e identidades (SILVA, 1998). Ou seja, um currículo nunca é neutro: desde a seleção dos conteúdos, autores/as, materiais didáticos, perspectivas teóricometodológicas etc., tudo opera em torno da produção de sentidos e de relações de poder. Nesses termos, pensar em currículos de formação docente que contemplem gênero e sexualidade como questões importantes é uma operação ética, política, pedagógica e 
institucional atravessada por disputas e tensionamentos.

Assim, compreende-se que os currículos de formação inicial e continuada de professores/as precisam incorporar questões de gênero em suas disciplinas, conteúdos, metodologias. É preciso promover reflexões que sejam capazes de fazer com que os/as docentes compreendam a importância de atuar na perspectiva de gênero. Além disso, é preciso que esses temas sejam abordados a partir de dimensões de saber-fazer, em um esforço teórico-prático que visa formar professores/as para intervir em situações de violência, desrespeito, preconceito etc., lembrando que tais situações são frutos das relações de poder que perpassam a escola.

A escola é um importante espaço não apenas de transmissão do conhecimento culturalmente elaborado, mas também produtora de relações sociais que colaboram para a preservação ou desconstrução do status quo.

Perceber e pensar sobre as relações de poder que interagem na escola é uma forma de opor-se, de gerar resistência e tentar começar um novo capítulo. Um capítulo preocupado em tecer outro olhar, outra escuta, capaz de compreender e acolher as diversidades, vendo-as como uma forma de manifestação da identidade/subjetividade do sujeito. Espera-se que tais fatores possam auxiliar a criação de sujeitos capazes de compreender e conviver com as diversidades.

\section{Referências}

BRUNER, J. Actos de significado:más allá de larevolución cognitiva. Madrid: Alianza Editorial, 1990.

BUTLER, J. Problemas de gênero:feminismo e subversão da identidade. ed. 5. Rio de Janeiro: Civilização Brasileira, 2013.

CARVALHO, M. P. Mau aluno, boa aluna? Como as professoras avaliam meninos e meninas. Revista de estudos feministas. Florianópolis, p.554-574, 2004.

FOUCAULT, M. Vigiar e punir: nascimento da prisão. Petrópolis: Vozes, 2012.

FOUCAULT, M. Microfísica do poder. São Paulo: Graal, 2013.

FOUCAULT, M. História da sexualidade 1: a vontade de saber. São Paulo: Paz e Terra, 2014. 
HAHNER, J. Em busca de educação, emprego e voto. In: HAHNER, J. Emancipação do sexo feminino: a luta pelos direitos da mulher no Brasil, 1850-1940. Florianópolis: Ed. Mulheres; Santa Cruz: EDUNISC, 2003, p.115-181.

LOURO, G. L. Currículo, gênero e sexualidade. Porto: Porto Editora, 2000.

LOURO, G. L. Gênero, sexualidade e educação: uma perspectiva pós-estruturalista. Petrópolis: Vozes, 2008.

LOURO, G. L. Mulheres na sala de aula. In: PRIORE, M. D. História das mulheres no Brasil. São Paulo: Contexto, 2013, p. 123-150.

MOREIRA, A. F. B.; SILVA, T. T. Currículo, cultura e sociedade. São Paulo: Cortez, 1998.

PERROT, M. As mulheres ou os silêncios da história. Bauru: EDUSC, 2005.

PIERUCCI, A. F. Do feminismo igualitarista ao feminismo diferencialista e depois. In: BRABO, T. S. A. M. (org). Gênero e educação: lutas do passado, conquistas do presente e perspectivas futuras. São Paulo: Ícone, 2007, p.30-44.

REVEL, J. Dicionário de Foucault. Rio de Janeiro: Forense Universitária, 2011.

SALIH, S. Judith Butler e a teoria queer. Belo Horizonte: Autêntica Editora, 2013.

SILVA, T. T. Documentos de identidade: uma introdução às teorias do discurso. Belo Horizonte: Autêntica, 1999.

SCOTT, J. Gênero: uma categoria útil para a análise histórica. 2009. Disponível em: www.dhnet.org.br/direitos/textos/generodh/gen_categoria.html. Acesso em: 23 abr. 2020.

Recebido em setembro 2019.

Aprovado em maio 2021. 